\title{
Calculation of structure-borne sound in a direct drive wind turbine
}

\author{
Martin Cardaun ${ }^{1}$ iD · Ralf Schelenz ${ }^{1}$ - Georg Jacobs ${ }^{1} \cdot$ Tobias Duda $^{1}$
}

Received: 30 November 2020 / Accepted: 8 February 2021 / Published online: 25 February 2021

(c) The Author(s) 2021

\begin{abstract}
In this publication, the methods will be presented that are deployed to formulate a multi-physical system model of a direct drive wind turbine in order to calculate structure borne sound. The model includes excitation effect as well as sound radiating behaviour. The mechanical structure as a medium partner between excitation and radiation will be formulated through a multi-body simulation model in the time domain. In the multi-body simulation model, all relevant drivetrain components are considered with their structural eigenmodes in the frequency range of interest. The electromagnetic forces of the multi-pole ring generator are calculated and introduced into the mechanical structure at each stator tooth, rotor pole and various axial positions individually. Similarly, the modelling of the bearings is investigated for a range of available methods. Sound emission is evaluated at the large outer surface structures like tower, blades and nacelle cover. To minimize computational effort, the surface accelerations are not calculated for each surface node, instead a modal approach is used. Through a combination of mode shapes with mode participation factors of the respective structures, the surface accelerations can be regained during a post-processing step. Those results are used as input for airborne sound calculations. Nevertheless, the high number of modal and spatial degrees of freedom results in high computing costs.
\end{abstract}

\section{Berechnung des Körperschalls in einer direkt angetriebenen Windkraftanlage}

\section{Zusammenfassung}

In dieser Publikation werden die Methoden vorgestellt, die zur Formulierung eines multiphysikalischen Systemmodells einer direkt angetriebenen Windenergieanlage eingesetzt werden, um den Körperschall zu berechnen. Das Modell umfasst sowohl die Anregungswirkung als auch das Schallabstrahlungsverhalten. Die mechanische Struktur als Medium zwischen Anregung und Abstrahlung wird durch ein Mehrkörpersimulationsmodell im Zeitbereich formuliert. In dem Mehrkörpersimulationsmodell werden alle relevanten Antriebsstrangkomponenten mit ihren Struktureigenmoden im Frequenzbereich von Interesse berücksichtigt. Die elektromagnetischen Kräfte des mehrpoligen Ringgenerators werden berechnet und an jedem Statorzahn, Rotorpol an verschiedenen axialen Positionen einzeln in die mechanische Struktur eingeleitet. In ähnlicher Weise wird die Modellierung der Lager für eine Reihe von verfügbaren Methoden untersucht. Die Schallemission wird an den großen äußeren Oberflächenstrukturen wie Turm, Blätter und Gondelverkleidung ausgewertet. Um den Rechenaufwand zu minimieren, werden die Oberflächenbeschleunigungen nicht für jeden Oberflächenknoten berechnet, sondern ein modaler Ansatz wird verwendet. Durch eine Kombination von Modenformen mit Modenbeteiligungsfaktoren der jeweiligen Strukturen können in einem Post-Processing-Schritt die Oberflächenbeschleunigungen zurückgewonnen werden. Diese Ergebnisse werden als Input für Luftschallberechnungen verwendet. Die hohe Anzahl an modalen und räumlichen Freiheitsgraden führt jedoch zu einem hohen Rechenaufwand.

\section{Motivation}

Martin Cardaun

martin.cardaun@cwd.rwth-aachen.de

1 Center for Wind Power Drives, RWTH Aachen University, 52062 Aachen, Germany
The expansion of renewable energy sources in Germany is substantially driven by wind power. One limiting factor for increasing wind power capacities is the sound emission of wind turbines. Both legal limitations as well as the acceptance of residents must be satisfied [6]. According to legal 


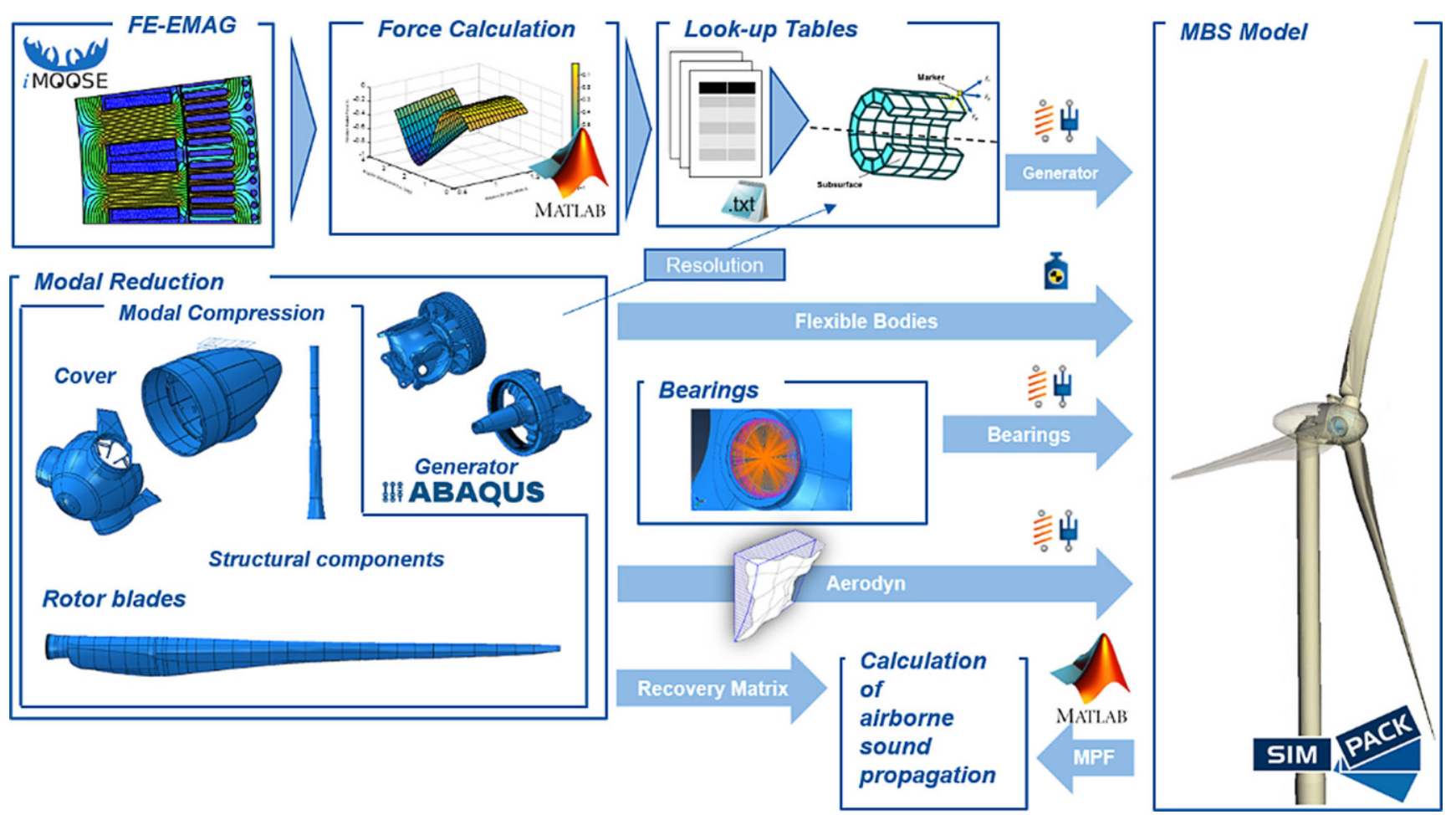

Fig. 1 Simulation chain for a direct drive wind turbines acoustic

regulations a sound immission measurement is to be performed in the vicinity of the turbine [7]. In order to avoid downtimes or artificial down-regulating of the turbine, the sound emission of a turbine needs to be addressed already in the design process. To address the acoustic behaviour of wind turbines in an early design stage, accurate numerical models need to be developed.

While the majority of research dedicated to wind turbine acoustics aims to understand the aerodynamic sound coming from the interaction of turbulent inflow and wind turbine blades, lesser work is carried out regarding tonal sound that is excited in the turbines drive train [10-14]. Advances in the field of broadband aerodynamic sound reveals the need to address tonal emission in the future. Here a variety of work was carried out already $[9,15]$.

To improve understanding of the acoustic transfer paths of the mechanical sound between excitation and radiation in gearless wind turbines a multi-physical system model of a direct drive wind turbine is derived. The aim is to localize the acoustic emission sources so that measures can be applied without the need for physical prototypes. Next to the modelling of the mechanical structure a model of the electromagnetic excitation forces in the system needs to be developed and coupled with the structure $[1,2]$.

\section{Modeling approach}

In this section the modelling method of a simulation tool, in the form of a multi-body simulation (MBS) model, for the calculation of surface accelerations on the turbine structure of a gearless wind turbine is presented. Fig. 1 schematically shows the entire simulation chain.

In the entire simulation chain of this project, electromagnetic excitation forces, structure-borne sound transfer, radiation and airborne sound propagation are simulated. The focus here lies on the prediction of tonal sound which is generated by periodic excitations at the generator. In this publication, the methodology for the calculation of structure-borne sound propagation from excitation to radiation at the component surfaces is presented.

The electromagnetic excitation forces are introduced into the MBS model via a specially developed interface. For this purpose, the forces acting on the rotor and stator are simulated in advance by means of a finite element (FE) simulation of the electromagnetic field for all operating points. The calculated force distributions are stored in the form of lookup tables and applied to the MBS model by a user force element [3]. This force element applies forces to nodes that are distributed over the rotor poles and stator teeth. In the current model every stator tooth is referenced with 4 nodes and every rotor pole with 3 nodes axially leading to a high number of flexible degrees of freedom for the stationary and rotating structure (Table 1). In future releases, the number 
Table 1 Number of DOF for all wind turbine components

\begin{tabular}{lllll}
\hline Model & Flexible DOF & Bearing DOF & Generator DOF & Other DOF \\
Stationary structure & 253 & $18,654,1229$ & 6840 & 60 \\
Rotating structure & 136 & $30,1350,2685$ & 882 & 108 \\
Rotor blade & $2338^{\mathrm{a}}$ & $6,366,729$ & 222 & - \\
Tower & $1510^{\mathrm{a}}$ & $6,402,801$ & 18 & 6 \\
Model & Flexible DOF & & Connection DOF \\
Stationary cover & 446 & & 78 & 108 \\
Rotating cover & 325 & & \\
\hline
\end{tabular}

acompressed

of nodes that are necessary to apply the loads can be further reduced to optimize computational costs.

The calculated surface accelerations are used in a further step to determine the emitted airborne sound and the resulting sound intensity at selected positions near the wind turbine. The Boundary Element Method (BEM) is used, in combination with a consideration of the rotating rotor (Doppler Effect) and a moving propagation medium (wind speed) [8].

To calculate the propagation of structure-borne sound and the surface accelerations in the time domain, a multibody simulation model of the mechanical components was created. The wind turbine model includes the drive train with rotating and stationary structure as well as the largearea structural components tower, rotor blades and nacelle cover.

All components are represented as flexible bodies. For this purpose the structures were modelled in a FE environment and a modal reduction was carried out according to Craig-Bampton [4]. To be able to describe acoustic effects up to $300 \mathrm{~Hz}$ sufficiently, the structural dynamics up

Fig. 2 Schematic comparison of methodologies for bearing modeling depth (top) and the respective nodes and coupling constraints in FE (bottom)

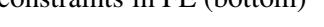

to $450 \mathrm{~Hz}$ are considered. This number is derived from the fact that all relevant excitations of the observed generator oscillate with up to $300 \mathrm{~Hz}$. This means that all structural eigenmodes up to $450 \mathrm{~Hz}$ are calculated and considered in the multi-body simulation. This results in an unconventionally high number of elastic degrees of freedom (DOF) for multibody simulations (Table 1). To optimize calculation costs a new method of modal compression was developed to compress the mode set of the flexible bodies as part of the ongoing research project.

A special focus of the modeling lies on the rotary bearings. These consist of the main bearing as well as the pitch and azimuth bearing. Due to the relative movements that the MBS model must be able to perform, a continuous FE modeling of the entire structure cannot be performed. Therefore, methods are needed to describe the interaction of the assemblies at the bearing locations (Fig. 2). The simplest possibility is the coupling of the components by rigid joints located along the rotational axis of the bearing, with a rotational degree of freedom in that axis. Corresponding couplings have to be considered in the FE-model. Here the
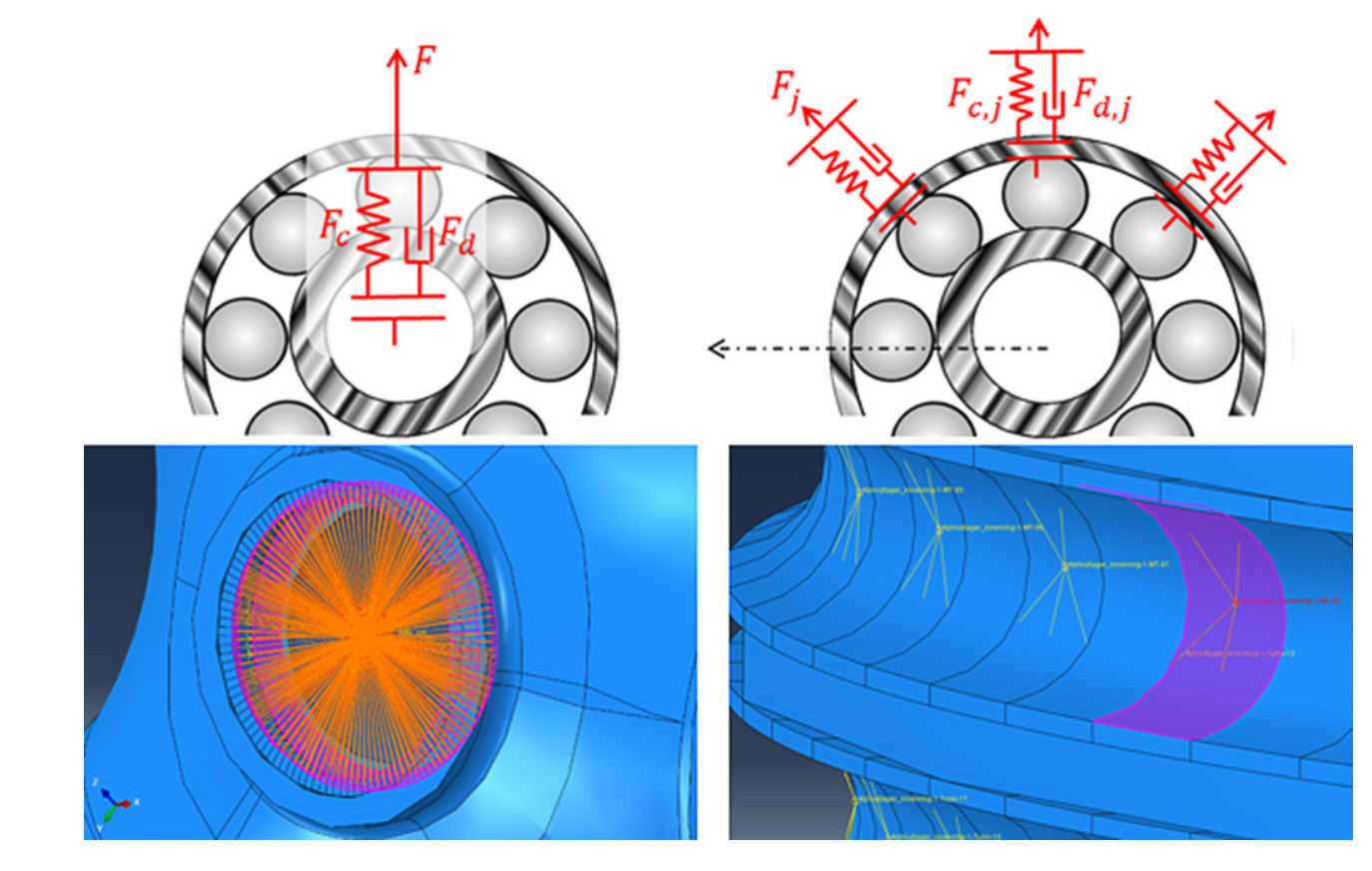
Fig. 3 Transfer function between torsional airgap moment and blade root acceleration for various bearing models

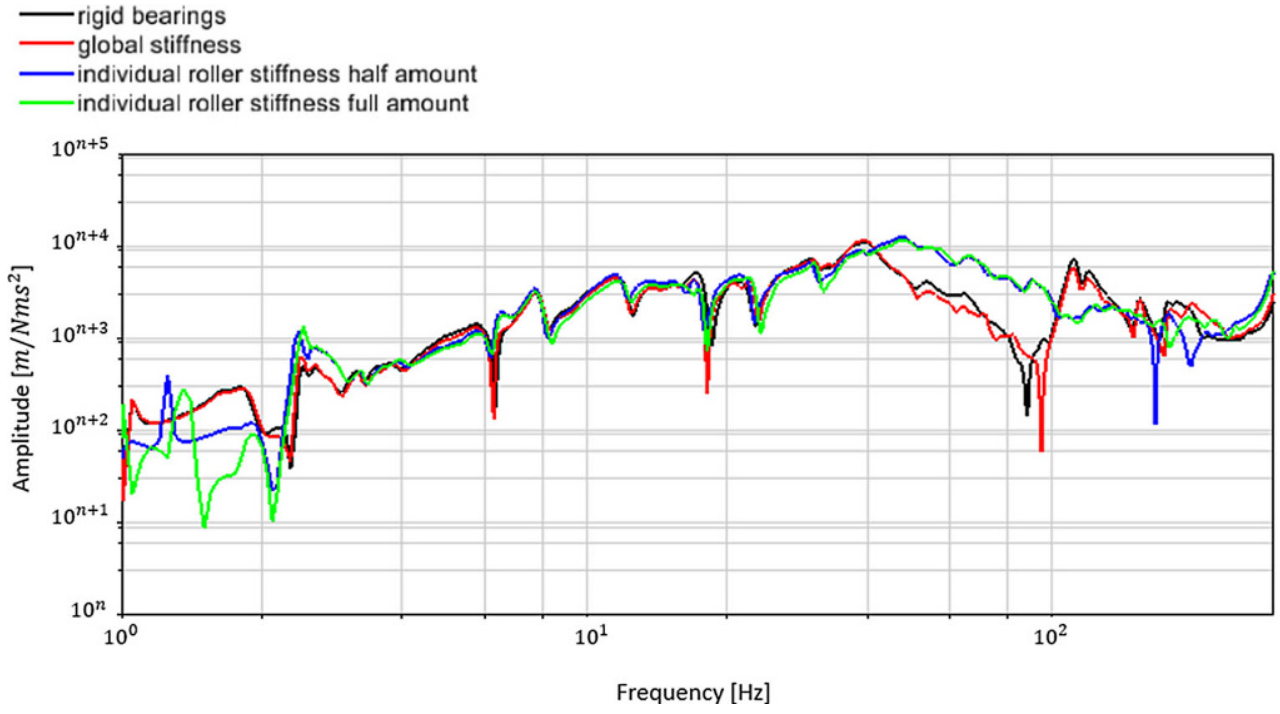

flexibility of the rolling elements as well as the load distribution on the raceways is neglected and loads pass the bearing unchanged. A more advanced method is the definition of a spring-damper force element. The input parameters are derived from static load calculations of the respective rollers FE models. Thus the flexibility of the bearing is considered as a whole, but the load distribution on the raceway is still being neglected. A further step towards a more sophisticated representation of the load transmission through rolling bearings can be taken by using specially developed force routines. The used software Simpack offers a force element developed for this application. Here, nodes distributed on the roller raceways are considered. The loads of the individual rollers are calculated and applied locally. Thus both the bearing flexibility and the load distribution are taken into account. The number of nodes is arbitrary. One node per rolling element is recommended. However, it is also investigated what influence a reduction by the factor 2 has on the simulation results in order to save further calculation costs. The resulting DOF for the various bearing models are also listed in Table 1 . The influence of the different methods of bearing formulation on the structureborne sound transfer is described in Chap. 3 .

The model created also includes a routine for calculating the aerodynamic excitation forces acting on the rotor blades and the tower. For this purpose, the AeroDyn code is used, which is connected to the MBS model via a force element interface and corresponding nodes so that any wind condition can be prescribed by the user [5].

Since the direct measurement of the acceleration of all surface nodes with the corresponding sampling rate would lead to very large amounts of data, the surface accelerations are described using Modal Participation Factors (MPF). In this context it is made use of the fact that elastic deformations of flexible bodies are formulated as a superposition of all elastic DOF in the multibody simulation. A time series of the deflection of each elastic DOF is written by the MBS solver. The deformation of the structure corresponding to each elastic DOF is stored in a recovery matrix during modal reduction. Thus, the deformation for each surface node can be regained in a post processing step and be used as an input for the calculation the airborne sound propagation.

\section{Results and discussion}

In this section the exemplary results of an evaluation of the transmission behaviour between an excitation in the generator airgap and the sound emitting surfaces of the rotor blades and tower will be shown. The turbine is subjected to a wind inflow with a speed of $14 \mathrm{~m} / \mathrm{s}$. Due to the aerodynamic forces acting on the structure and the opposing generator torque, the turbine is rotating with $13.1 \mathrm{rpm}$. In this state additional excitation forces and moments are applied to the generator structure. For a better understanding of the occurring effects, each excitations spatial direction is observed individually. They are super-positioned with the airgap loads according to the respective operation point. Transfer functions between the excitation loads and accelerations on the sound emitting structures are derived in order to evaluate the different approaches used for modelling the bearings. The most basic model uses rigid joint at the bearing locations. The second model consists of springdamper force elements that consider the bearing as a single nonlinear stiffness curve for each DOF. A more advanced approach is the use of individual stiffness for each roller. Here a model with half as many coupling nodes and a model with the full amount of coupling nodes are deployed. 
Fig. 4 Transfer function between torsional airgap moment and tower flange acceleration for various bearing models

Fig. 5 Transfer function between vertical airgap force and blade root acceleration for various bearing models

Fig. 6 Transfer function between vertical airgap force and tower flange acceleration for various bearing models
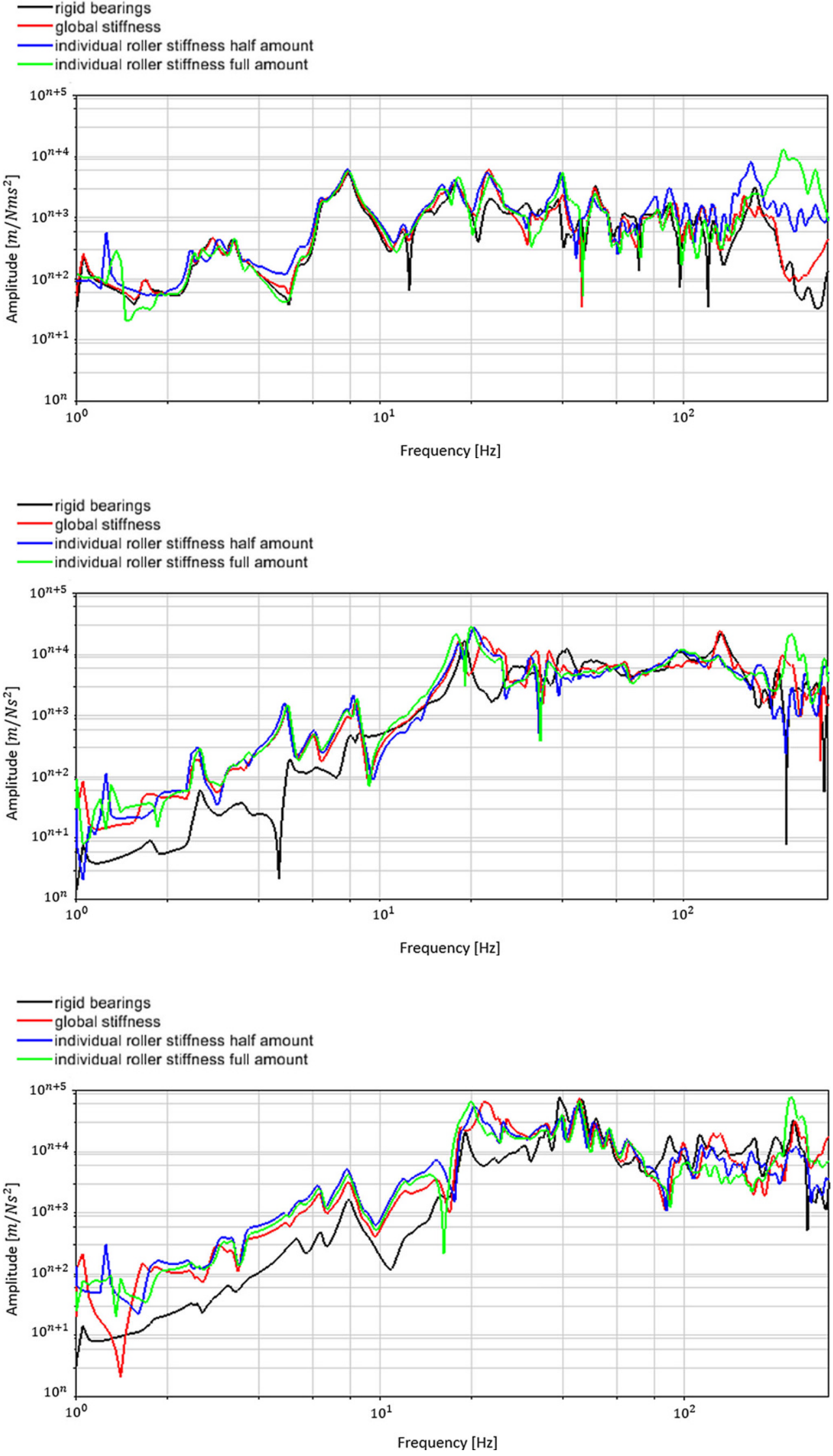
At first, the surface of the rotor blade close to the pitch bearing is observed. Fig. 3 shows the transfer function between the excitation and the structure acceleration of the blade as a result of an excitation in form of a generator torque. The exponent $n$ has the same value for all following figures as well. The blade is pointing towards the ground, leading to a radial direction of the excitation as seen from the pitch bearing. Using a rigid bearing or a single stiffness shows no significant difference over the frequency range of 0 to $300 \mathrm{~Hz}$. When individual roller stiffness is considered, the transmission shows similar results between $4 \mathrm{~Hz}$ and $40 \mathrm{~Hz}$. Above and below the results deviate, especially around $90 \mathrm{~Hz}$. In the lower frequency range also the number of considered roller nodes has an influence on the load transmission through the bearing. In the range above $2 \mathrm{~Hz}$ amplitudes appear to increase one magnitude and higher than below.

A similar analysis was carried out for the tower structure which is also relevant for emitting sound next to the rotor blades. Fig. 4 shows the transfer function between the same excitation load as above and the acceleration of the tower structure close to the azimuth bearing. Again the excitation leads to a radial force on the azimuth bearing. The structure response shows similar behaviour under $100 \mathrm{~Hz}$. Above that frequency all four methods show an individual characteristic.

When an excitation in form of a vertical force is introduced to the generator structure, the following transfer functions can be derived between the excitation load and the acceleration at the respective locations on rotor blade and tower (see Fig. 5 and 6). In this configuration the excitation passes the pitch and azimuth bearing axially. Again, first the load transfer between generator and rotor blade is shown in Fig. 5. In the lower frequency range below $10 \mathrm{~Hz}$ the rigid bearing model differs mostly from the three more advanced models. Above $10 \mathrm{~Hz}$ the results show smaller deviations. Fig. 6 shows the results for the load transmission to the tower. In agreement with the results of the rotor blade, the rigid model is mostly set apart, especially in the lower frequency range.

The results obtained in this analysis support the use of advanced models for bearings when results for a broad frequency range are of interest. For the transmission of axial loads a global stiffness could provide sufficient accuracy, since axial load is distributed in a more even manner over all rollers. When radial load transmission occurs at a bearing, individual stiffness for rollers is more accurate because the loading situation differs significantly below the rollers.

\section{Conclusions}

In this publication the approach for formulating a multiphysical direct-drive wind turbine model for calculating structure borne sound transfer and emission in the time domain was presented. Different aspects of this novel simulation chain from excitation, transmission and radiation are explained and discussed. Also results are shown in the course of an example load scenario simulation that is carried out at rated wind speed. The impact of various modelling methods on the transfer was investigated. It is suggested that a consideration of individual roller stiffness leads to improved results regarding the structure response to excitations in the drive train.

In future research the model will be validated with turbine measurements. This offers the possibility to detect the optimal modelling depth for generator, bearings and structural components. Critical transfer paths will be identified so that appropriate measures can be taken to reduce the turbines sound radiation.

Acknowledgements This research was funded by Federal Ministry for Economic Affairs and Energy of Germany. We also thank our project partners, who provided equipment, insight and expertise that greatly assisted the research.

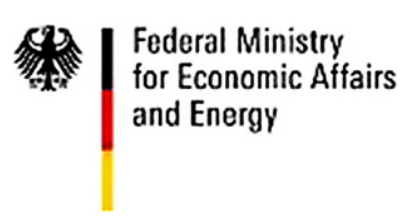

Funding Open Access funding enabled and organized by Projekt DEAL.

Conflict of interest M. Cardaun, R. Schelenz, G. Jacobs and T. Duda declare that they have no competing interests.

Open Access This article is licensed under a Creative Commons Attribution 4.0 International License, which permits use, sharing, adaptation, distribution and reproduction in any medium or format, as long as you give appropriate credit to the original author(s) and the source, provide a link to the Creative Commons licence, and indicate if changes were made. The images or other third party material in this article are included in the article's Creative Commons licence, unless indicated otherwise in a credit line to the material. If material is not included in the article's Creative Commons licence and your intended use is not permitted by statutory regulation or exceeds the permitted use, you will need to obtain permission directly from the copyright holder. To view a copy of this licence, visit http://creativecommons.org/licenses/by/4. $0 /$.

\section{References}

1. Duda T, Jacobs G, Bosse D (2019) Investigation of modeling depths for an electromechanical simulation of a direct-drive generator considering parasitic airgap forces and external loads. J Phys Conf Ser 1222:12029 
2. Duda T, Jacobs G, Bosse D (2019) Electromechanical simulation of a direct-drive generator considering parasitic magnetic forces and external loads. In: 2019 Conference for Wind Power Drives (CWD), Aachen

3. Mülder C, Jacobs G, Duda T, Hameyer K (2019) Model approach for electromagnetically excited mechanical vibrations in directdrive wind turbines. J Phys Conf Ser 1618:22060

4. Craig R, Bampton M (1968) Coupling of substructures for dynamic analysis. AIAA J 6(7):1313-1319

5. Jonkman J, Hayman B, Jonkman B, Damiani R, Murray R (2015) AeroDyn v15 user's guide and theory manual. National Renewable Energy Laboratory, Golden (Technical report)

6. Bundes-Immissionsschutzgesetz (32. BImSchG): Geräte- und Maschinenlärmschutzverordnung vom 29. August 2002 (BGB1. I S. 3478), die zuletzt durch Artikel 110 der Verordnung vom 19. Juni 2020 (BGB1. I S. 1328) geändert worden ist

7. IEC (2002) Wind turbine generator systems-Part 11: Acoustic noise measurement techniques: IEC 61400-11. International Electrotechnical Commission, (Second Edition 2002-12)

8. Dilba B, Markiewicz M, von Estorff O (2017) Toolchain zur Simulation tonaler Schallabstrahlung einer Windenergieanlage. In: VDIFachtagung Schwingungen von Windenergieanlagen, Bremen
9. Dilba B, Markiewicz M, von Estorff O (2016) Modellierung einer Windenergieanlage zur Untersuchung tonaler Schallabstrahlung. In: DAGA Aachen 2016, Aachen

10. Zhu W, Shen W, Barlas E, Bertagnolio F, Sørensen J (2018) Wind turbine noise generation and propagation modeling at DTU wind energy: a review. Renew Sustain Energy Rev 88:133-150

11. Bhargava V, Samala R (2019) Acoustic emissions from wind turbine blades. J Aerosp Technol Manag 11(1):14. https://doi.org/10. 5028/jatm.v11.1071

12. Ghasemian M, Nejat A (2015) Aerodynamic noise prediction of a horizontal axis wind turbine using improved delayed detached Eddy simulation and acoustic analogy. Energy Convers Manag 99:210-220

13. Wasala S, Storey R, Norris S, Cater J (2015) Aeroacoustic noise prediction for wind turbines using large Eddy simulation. J Wind Eng Ind Aerodyn 145:17-29

14. Klein L, Gude J, Wenz F, Lutz T, Krämer E (2018) Advanced computational fluid dynamics (CFD)-multi-body simulation (MBS) coupling to assess low-frequency emissions from wind turbines. Wind Energy Sci 3:713-728

15. Marmo B, Carruthers B (2010) Modelling and analysis of acoustic emissions and structural vibration in a wind turbine. In: Proceedings of the COMSOL Conference 2010 Paris, Paris 